\title{
Oxygen mass transfer studies on batch cultivation of $P$. aeruginosa in a biocalorimeter
}
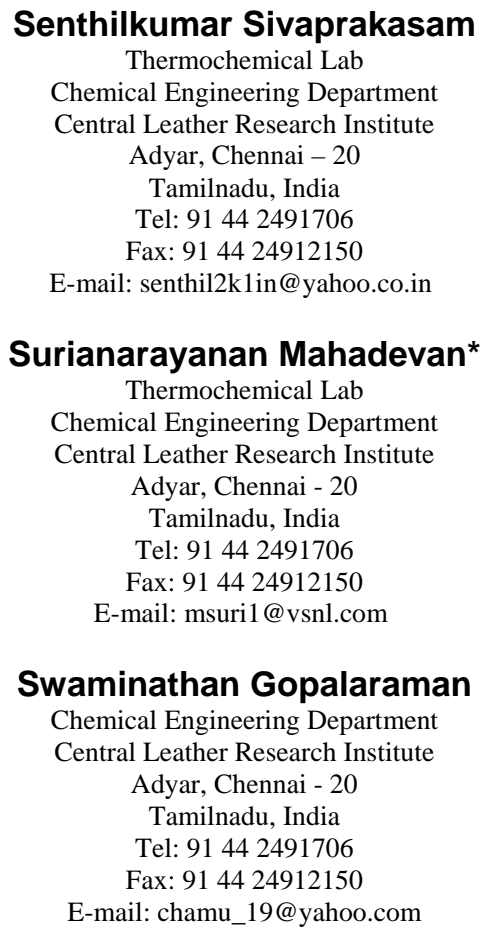

Financial support: Council for Scientific and Industrial Research (CSIR) Fellowship.

Keywords: biocalorimeter, metabolic heat, $P$. aeruginosa, scale-up, volumetric mass transfer coefficient.

$\begin{array}{ll}\text { Abbreviations: } & \text { DO: dissolved oxygen } \\ & \text { OTR: oxygen transfer rate } \\ & \text { OUR: oxygen uptake rate }\end{array}$

In the present work volumetric mass transfer coefficient $\left(k_{L} a\right)$ was investigated during batch cultivations of Pseudomonas aeruginosa on a nutrient media. The effects of process variables (viz. impeller speed, oxygen flow and geometry of impeller) on the volumetric mass transfer coefficient of oxygen, $k_{L} a$, in a biocalorimeter (Bio-RC1) was investigated and reported in this research work. The experimental data have been analyzed employing MATLAB to obtain the influences of the process parameters on $k_{L} a$. An attempt was made to correlate volumetric mass transfer coefficient with metabolic heat production rate at optimized process conditions. The correlation reported in this work would be useful to control and scale up of bioprocesses.

With the recent activities for developing biological processes on industrial scale, there is a need for evolving robust design and scale-up methods for bioreactors. Bioreactor design is a complex engineering task (GarciaOchoa and Gomez, 2000; Garcia-Ochoa and Gomez, 2005). Under optimum conditions the microorganisms or cells will reproduce at an astounding rate. The vessel's geometry and operating conditions like gas (i.e., air, oxygen, nitrogen, carbon dioxide) flow rates, temperature, $\mathrm{pH}$ and dissolved oxygen (DO) levels, and agitation speed have to be closely monitored and controlled. One of the key issues in aerobic bioreactor design is oxygen transfer (Galaction et al. 2004). Oxygen transfer in aerobic bioprocesses is essential and shortage of it would drastically affect the process performance. Bioprocesses are usually carried out in aqueous media, where the solubility of oxygen is very low owing to the presence of ionic salts and nutrients. At the

*Corresponding author 
same time the rate of oxygen utilization by the microorganisms is rather high. Oxygen transfer through microbial cells controls the most of aerated biological systems. The amount of DO into the broths is limited by its solubility and mass transfer rate, as well as by its consumption rate on cells metabolic pathways (Calik et al. 1997).Oxygen transfer is usually helped by agitation, and is also for mixing nutrients and to keep the system homogeneous. There are, however, limits to the speed of agitation, due to high power consumption (which is proportional to the cube of the speed of the electric motor) and the damage to organisms due to excessive tip speed. Gas-liquid mass transfer is commonly the rate-limiting step in industrial-scale biochemical reactions. For this reason, bioreactor design and scale-up focuses on providing ample gas mass transfer. The oxygen mass transfer can be described and analyzed by means of volumetric mass transfer coefficient, $k_{L} a$. It represents the most important parameter implied on the design and operation of mixingsparging equipment of the bioreactors. Maintaining a constant volumetric mass-transfer coefficient is a common scale-up strategy (Ozbek and Gayik, 2001). The oxygen mass transfer rate in a bioreactor depends on several factors, such as the geometry of the bioreactor (type of bioreactor, distributor or stirrer design, etc.), the liquid properties (viscosity, superficial tension, etc.), and the dissipated energy in the fluid, which depends on the airflow rate, the stirrer speed, etc. Therefore, composition and rheological properties of the medium changing with time have an important effect on mass transfer rate (Montes et al. 1999; Chisti et al. 2002). Thus the coefficient $\left(k_{L} a\right)$ plays an important role in design, scale-up and economy of the process.

Most of the volumetric mass transfer coefficient correlations in the literature belong to two categories. In the first kind $k_{L} a$ is correlated to stirrer speed (or power input per unit volume) and superficial gas velocity, and in the case of the non-Newtonian fluids the broth viscosity must be also taken into account (Garcia-Ochoa and Gomez, 1998). The second category includes empirical correlations based on dimensionless numbers (Nishikawa et al. 1981), i.e., expressing the dependence of the Sherwood number as a function of the Reynolds, Weber and Aeration numbers. Biocalorimeter (RC1) is a bench scale bioreactor widely applied to investigate several biochemical reactions using the metabolic heat generated due to metabolic activity (Marison et al. 1998). Though lot of studies has been dealt on thermodynamics of microbial growth using biocalorimeter, knowledge of mass transfer occurring simultaneously with metabolic heat generation is feeble (which is more important when the calorimetric results are used for bioreactor scale-up work). The present study aims to determine the influence of process variables such as impeller speed and oxygen flow rate on the gas-liquid mass transfer of oxygen in a biocalorimeter. Correlations for $k_{L} a$ are needed to be developed for biocalorimeter, which could immensely help for efficient scale up of calorimetric results for large scale level. Using a bench-scale biocalorimeter, with a single impeller and a capacity of $1 \mathrm{l}$ (total volume), the effects of process variables on the $k_{L} a$ were investigated. Later, $k_{L} a$ values were analyzed to establish correlations with impeller speed and oxygen flow rate. From the established correlations, the numerical values for the exponents $(\alpha, \beta)$ were determined. A correlation was also developed between $k_{L} a$ and metabolic heat (q) at optimized process conditions.

\section{MATERIALS AND METHODS}

\section{Organism}

The organism used for oxygen transfer studies was $P$. aeruginosa (BC1) isolated from tannery soak liquor. Isolate BC1 was confirmed as $P$. aeruginosa by its positive oxidase reaction (Kovacs, 1956), oxidative utilization of glucose (Hugh and Leifson, 1953) and production of pyocyanin on Pseudomonas Isolation Agar (PIA; Himedia, Mumbai, India). The strain was further confirmed with biochemical analysis performed at Institute of Biomedical Sciences (IBMS, Chennai, India). The isolated strain was halotolerant (up to $4 \% \mathrm{NaCl}$ by wt) in optimized growth conditions and its high proteolytic activity even at saline conditions made it a suitable organism for soak liquor treatment.

$P$. aeruginosa was maintained in glycerol stock under frozen conditions $\left(-20^{\circ} \mathrm{C}\right)$. A loop full of colonies was streaked on nutrient agar plates and incubated for 24 hrs at $37^{\circ} \mathrm{C}$. Well grown individual pure colonies were transferred aseptically to NB media and incubated in a shaker till it reached its exponential phase, which would serve as inoculum for all the experiments.

\section{Media}

Nutrient broth (a complex growth media) was used for cultivation of $P$. aeruginosa in all oxygen uptake experiments. NB medium consists of Peptone $10 \mathrm{~g} \mathrm{l}^{-1}$; Yeast extract $3 \mathrm{~g} \mathrm{l}^{-1}$; $\mathrm{NaCl} 5 \mathrm{~g} \mathrm{l}^{-1}$; ( $\mathrm{pH} \mathrm{7.0).} \mathrm{pH}$ adjusted to 7.0 by adding $\mathrm{NaOH}$ and $\mathrm{HCl}$ solutions respectively using a $\mathrm{pH}$ meter. Nutrient agar medium (Himedia, MO12) was used for preservation of pure strain. All mediums were sterilized in an autoclave at $120^{\circ} \mathrm{C}$ and 15 psi pressure respectively.

\section{Biocalorimeter}

All the experiments have been carried out in a biological reaction calorimeter (Bio-RC1, Mettler-Toledo, AG, Switzerland) with 11 of working volume (Internal dia 8.2 $\mathrm{cm} \&$ Height of reaction broth on reactor $15 \mathrm{~cm}$ ), equipped with DO (Schott, Oxy12) and temperature probes (Figure 1). Agitation was provided with a 4-blade turbine impeller (0-1000 rpm) type with a ratio of stirrer/tank diameters $(\mathrm{D} / \mathrm{T})$ of 0.44 . Oxygenation was performed by supplying iolar grade pure oxygen from an oxygen cylinder and the flow was controlled by a rotameter. The inlet oxygen was sterilized through a membrane filter $(0.2 \mu \mathrm{m})$ and sparged 
in to the bottom of the reactor. In this study, 2 different stirrers viz. Turbine-impeller type (4-bladed and $4 \mathrm{~cm}$ dia) and a Rushton-turbine type (4-bladed and $4 \mathrm{~cm}$ dia) of 1 $\mathrm{mm}$ of thickness were used to investigate the oxygen mass transfer 'L-bend' type gas sparger ( $4 \mathrm{~cm}$ long) with holes of $0.5 \mathrm{~mm}$ diameter was employed for oxygen supply. Oxygen uptake studies were performed at isothermal mode and the reactant temperature $\left(T_{r}\right)$ was maintained constant by controlling the jacket temperature $\left(T_{j}\right)$. This was done by circulating at high rate $\left(2 \mathrm{ls}^{-1}\right)$ low-viscosity silicone oil through the reactor jacket. The jacket temperature was carefully controlled by blending oils from 'hot' and 'cold' circuits, via an electronically controlled metering valve. Heat generated from the biological reactions was monitored by WINRC software (Marison et al. 1998), which acquired the temperatures of both reactor $\left(T_{r}\right)$ and jacket $\left(T_{j}\right)$ and evaluated the value for heat production rate.

The measured heat production rate ( $\mathrm{q}$ in $\mathrm{W}$ ) is given by

$$
q=U A\left(T_{r}-T_{j}\right)
$$

Where $\mathrm{U}$ is the global heat transfer coefficient in $\left(\mathrm{W} \mathrm{K}^{-1}\right.$ $\mathrm{m}^{-2}$ ), A is the heat transfer surface in $\mathrm{m}^{2}, T_{r}$ is the reactor temperature in $\mathrm{K}$ and $T_{j}$ is the jacket temperature in ${ }^{\circ} \mathrm{C}$.

All the inlet and outlet streams were completely insulated to avoid heat loss due to heat bridge phenomenon. Baseline heat signal $\left(q_{b}\right)$ value is sum of heat effects due to aeration and stirring power apart from the measured heat of reaction $\left(q_{r}\right)$. After reaching a stable baseline heat signal $\left(q_{b}\right)$, the reaction was initiated by addition of inoculum and similar kind of stable baseline signal was observed at the end of the experiment (endogenous phase). This baseline heat value $\left(q_{b}\right)$ was carefully eliminated from the heat evolved due to biological reaction. The value of metabolic heat evolution during the bioprocess $\left(q_{r}\right)$ could simply be determined by deducting the measured $q$ (from Equation 1) from that of the base-line signal. Hence the metabolic heat production rate $\left(q_{r}\right)$ is given as follows:

$$
q-q_{b}=U A\left(\Delta T-\Delta T_{b}\right)=q_{r}
$$

The UA factor was determined for each run at regular time intervals by means of in situ calibration electrical heater provided in calorimeter (Hariri et al. 1996).

\section{Operational conditions}

The experimental work has been carried out in a complex growth (NB) media, maintaining optimum operational conditions ( $\mathrm{pH} 7.0,37^{\circ} \mathrm{C}$ and $2 \%$ seed culture conc.). The oxygen flow rate was varied in the range of 0.5-1.5 $\mathrm{l} \mathrm{min}^{-1}$ and the stirrer speed was changed from $50 \mathrm{rpm}$ to $250 \mathrm{rpm}$. A minimum critical DO concentration up to $10 \%$ saturation value (2 ppm) was maintained to ensure pure aerobic conditions i.e. the minimum requirement of $\mathrm{DO}$ for obligatory aerobic organism such as $P$. aeruginosa.

\section{Analytical methods}

Biomass concentration was determined by centrifuging the culture sample taken from the calorimeter in an ultracentrifuge (Sigma, Model no. 3K30) at $10000 \mathrm{rpm}$ for $10 \mathrm{~min}$. The harvested biomass was dried in an oven for 24 hrs at $105^{\circ} \mathrm{C}$. The cell dry biomass was estimated gravimetrically. DO was monitored online by means of a polarographic electrode obtained from $\mathrm{M} / \mathrm{s}$. Schott, Germany (OXY12 Model).

\section{Experimental determination of OUR, OTR and $k_{L} a$}

Dynamic method (Singh, 1996) was used for measuring OUR (oxygen uptake rate) and $k_{L} a$ in the calorimeter by using polarographic DO probe.

The following mass balance equation for the DO in batch reaction can be established:

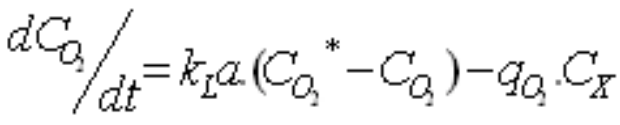

where the first term on the right hand side of Equation (3) is the oxygen transfer rate (OTR) and the second term is the volumetric OUR of the culture. The measurement of OUR and OTR can be made using the dynamic technique, in two stages (Figure 2). In the first stage, the inlet of airflow to the broth is interrupted, and a decrease of DO concentration due to cellular respiration is observed, which was recorded by a polarographic oxygen probe. The volumetric OUR is determined by noting the changes in the DO concentration when the oxygen flow was stopped.

Equation (3) can be simplified to:

$$
d C_{O_{2}} / d t=-q_{O_{2}} \cdot C_{X}
$$

The DO concentration should be maintained higher than $10 \%$ of saturation value to ensure that the microorganisms are not damaged due to lack of oxygen. The volumetric OUR is obtained from the slope of the linear regression of the change in DO concentration vs. time. This first stage is employed to obtain the value of the specific OUR $\left(q_{o_{2}}\right)$ by the microorganism, by dividing the volumetric OUR by the biomass concentration. In the second stage the inlet of oxygen flow to the broth is restarted (stirrer speed and airflow rate are fixed at predetermined values) and this lead to increase in DO concentration. Oxygen flow was maintained till the DO concentration $\left(\overline{C_{\mathrm{O}_{2}}}\right)$ reached the steady state value. Under these conditions Equation (3) can be integrated, taking into account the moment at which the oxygen supply of the culture began $\left(t=t_{1} \therefore C_{\mathrm{O}_{2}}=C_{1}\right)$ 
and another time ( $t=t_{2} \therefore C_{O_{2}}=C_{2}$ ), yielding the equation:

$q_{O_{2}} \cdot C_{X} \cdot\left(t_{2}-t_{1}\right)+\left(C_{2}-C_{1}\right)=k_{L} a \cdot \int_{t_{2}}^{t_{1}}\left(\overline{C_{O 2}}-C_{O_{2}}\right) \cdot d t$ [5]

Equation (5) was used to determine the volumetric mass transfer coefficient. Equation 5 was solved by plotting $q_{\mathrm{O}_{2}} \cdot C_{X} \cdot+\frac{\left(C_{2}-C_{1}\right)}{\left(t_{2}-t_{1}\right)}$ against steady state DO concentration value $\left(\overline{C_{\mathrm{O}_{2}}}\right)$ for each data set of experimental values of DO concentration and time, to obtain volumetric mass transfer coefficient. Experiments were carried out for measuring both OUR and OTR at different stages of growth: lag, exponential and stationary stages. Volumetric mass transfer coefficient values, $k_{L} a$, have been determined in a wide range of operational conditions viz. impeller speed (50-250 rpm), oxygen flow (0.5-1.5 $\mathrm{l} \mathrm{min}^{-1}$ ) and impeller type (Rushton-Turbine \& Turbine). The measurements have been carried out changing the superficial gas velocity, $V_{s}$, as 0.00165 , 0.0003304 and $0.004976 \mathrm{~ms}^{-1}$, which corresponding to oxygen flow rates between $0.5,1$ and $1.51 \mathrm{~min}^{-1}$. The stirrer speed, N, was varied between 50 and $250 \mathrm{rpm}$ and simultaneously OUR, OTR and $k_{L} a$ values were determined.

\section{Correlation studies}

The oxygen mass transfer rate in the biocalorimeter with mechanical agitation of broth is a function of many variables, such as the physical properties of the liquid (viscosity, surface tension, etc.), the geometry of the vessel and stirrer, the type of sparger and the operational conditions. In the literature, both dimensional and dimensionless equations for the volumetric mass transfer coefficient have been proposed. In this work, the effect of impeller speed $(\mathrm{N})$, superficial gas velocity $\left(V_{s}\right.$, oxygen flow) and geometry of stirrer on oxygen mass transfer were extensively studied. Predictions about the rate of absorption of a gaseous species in a stirred tank is usually based on correlations of overall volumetric mass transfer coefficient $\left(k_{L} a\right)$ with mechanical agitation power per unit volume $\left(\mathrm{P} / \mathrm{V}_{\mathrm{L}}\right)$ and gas sparging rate expressed as the superficial velocity $\left(V_{s}\right)$. The power input per unit volume $\left(\mathrm{P} / \mathrm{V}_{\mathrm{L}}\right)$ and, superficial gas velocity $V_{s}$ are the major correlation coefficients for $k_{L} a$. Therefore, equations of the following type are frequently found in the literature (Vant Riet, 1979).

$$
k_{L} a=A\left[\frac{P}{V_{L}}\right]^{a}\left[V_{S}\right]^{\beta}
$$

where, $P$, is the mechanical agitation power in gas liquid dispersion (W); $\mathrm{V}_{\mathrm{L}}$, liquid volume $\left(\mathrm{m}^{3}\right) ; V_{\mathrm{s}}$, gas superficial velocity ( $\mathrm{m} \mathrm{s}^{-1}$ ); $A$, constant; $\alpha$ and $\beta$ are exponents. When $P$ is omitted an equation like the one following can usually be adapted.

$$
k_{L} a=A N D^{\alpha 1, \alpha 2}\left[V_{s}\right]^{\beta}
$$

Where, $D$ is the impeller diameter (m) and $N$ is the impeller speed. However, since the accurate measurement of the actual power input into the system may be quite cumbersome and many investigators (Wu, 1995) have chosen to use the Power factor term instead, i.e. $N^{3} D^{2}$ to represent the power input per volume. In this present work, $k_{L} a$ values obtained from the experimental data were plotted against the operating variables (stirrer speed and superficial gas velocity) and the correlation was obtained for power number $\left(N^{3} D^{2}\right)$ by performing multiple regression analysis in MATLAB (Version 7.0).

Attempts were made to correlate the heat production rate (q) with volumetric mass transfer coefficient $\left(k_{L} a\right)$ and a linear correlation was obtained at optimized process conditions.

\section{RESULTS AND DISCUSSION}

\section{Influence of stirrer type on the $k_{L} a$ values}

Figure 3 shows the plot of $k_{L} a$ values for these 2 types of stirrer (Turbine and Rushton-turbine type). It was clear from the Figure 3 that turbine-impeller type stirrer shows a maximum $k_{L} a$ value at all the growth phases of the culture and was fixed as a suitable impeller for oxygen mass transfer experiments. Oxygen mass transfer in Rushtonturbine type impeller was found to decrease with the biomass growth. This may be attributed to the increase in viscosity of broth media due to biomass growth and the inefficiency of Rushton-turbine type to break the bubbles effectively for enhanced mass transfer. Further, the high shear force caused a negative effect on growth of culture and made it unsuitable for further studies. Excessive foaming was also observed when Rushton-Turbine type impeller was used.

\section{The effect of impeller speed on the $k_{L} a$ values}

The effects of impeller speed (turbine) on the $k_{L} a$ was investigated using the impeller speeds in the range of 50$200 \mathrm{rpm}$ by maintaining constant working volume of $0.75 \mathrm{l}$, oxygen flow rate of $1 \mathrm{l} \mathrm{min}^{-1}$, temperature of $37^{\circ} \mathrm{C}$ and $\mathrm{pH}$ 7.0. Experiments were performed at respective impeller speeds starting from lag-phase until the culture reached its stationary phase. The values of $k_{L} a$ for different impeller speeds are plotted in Figure 4. The volumetric mass transfer coefficient, $k_{L} a$, increased from 0.1212 to $0.582 \mathrm{~min}^{-1}$ when the impeller speed was increased from 50 to $200 \mathrm{rpm}$. It can be also seen from the Figure 5 that further increase in impeller speed to $250 \mathrm{rpm}$ showed no significant rise in $k_{L} a$ 
value (results not shown). Hence an optimum stirrer speed of $200 \mathrm{rpm}$ was fixed for efficient oxygen mass transfer for the cultivation of $P$. aeruginosa. Analysis of biomass growth of $P$. aeruginosa at different impeller speeds also proved that $200 \mathrm{rpm}$ is an optimum value (Figure 5). Further increase in impeller speed to $250 \mathrm{rpm}$ caused a significant decrease in growth, perhaps due to inefficient oxygen transfer under high turbulence conditions. Further we also observed high foaming formation at $250 \mathrm{rpm}$. In order to prove the decrease in biomass growth rates at high stirrer speeds, the specific growth rates $(\mu)$ were estimated for all the evaluated conditions and shown in Figure 6. It can be seen that at $250 \mathrm{rpm}$ the specific growth rate decreases and supports our decision for fixing the stirrer speed to $200 \mathrm{rpm}$.

\section{The effect of oxygen flow rate on the $k_{L} a$ values}

The effects of oxygen flow rates on $k_{L} a$ were investigated and the values of $k_{L} a$ were plotted in Figure 7. Volumetric mass transfer coefficient, $k_{L} a$, increased from 0.181 to 0.41 $\min ^{-1}$ when the oxygen flow rate was increased from 0.5 to $1 \mathrm{l} \mathrm{min}$. Further increase in oxygen flow to $1.5 \mathrm{l} \mathrm{min}^{-1}$ show no improvement in mass transfer (results not shown). Cell dry weight was estimated at regular time intervals and specific OUR $\left(q_{o_{2}}, \mathrm{~min}^{-1}\right)$ was calculated. Figure 8 shows variation in $q_{\mathrm{o}_{2}}$ profiles with change in oxygen flow rates. From Figure 8, it was found that $q_{o_{2}}$ results also showing similar trend like $k_{L} a$ plot, where $1 \mathrm{l} \mathrm{min}{ }^{-1}$ was found to be optimum value.

\section{Calorimetric studies}

Metabolic heat generated due to the growth of $P$. aeruginosa in NB media at varying impeller speeds and oxygen flow rates were simultaneously measured in biocalorimeter and plotted against time. Figure 9 shows a typical power-time curve obtained for the growth of $P$. aeruginosa in NB media at optimized conditions $\left(11 \mathrm{~min}^{-1}\right.$ oxygen flow rate and $200 \mathrm{rpm}$ impeller speed). From the Figure 9, it was observed that the biomass growth profile was following closely the power-time curve and this clearly shows that growth of $P$. aeruginosa is directly proportional to metabolic heat generation. Both $q_{o_{2}}$ and heat values seem to be influenced by growth phases of $P$. aeruginosa. $q_{o_{2}}$, start to increase from lag phase and dramatically increases in exponential phase to a maximum value and then starts falling in endogenous phase (death phase). The same trend was observed in heat values during the growth of $P$. aeruginosa in NB media at each different operating condition. From Figure 9, the maximum value of $q_{o_{2}}$ was found to be $2.888 \mathrm{~min}^{-1}$ at the middle of the exponential phase and the max. heat generated also occurred at the same phase $(3.01 \mathrm{~W})$. Usually both the respirometric and calorimetric data provides similar information (Voisard et al. 2002) and was in good agreement with the experimental results. By analyzing the oxygen mass transfer and calorimetric results, the optimum impeller speed and oxygen flow rate were determined for the growth of $P$. aeruginosa.

Total metabolic heat generated (cumulative) till the exponential growth phase at varying impeller speed conditions were evaluated using WINRC software (MettlerToledo, AG, Switzerland) and compared in the plot shown in Figure 10. Heat added due to stirring power was systematically eliminated from the cumulative metabolic heat generated by performing baseline experiments (results not given). Figure 10 clearly depicts that the metabolic heat production was increased approximately 4 -fold when the impeller speed was raised from 50 to $200 \mathrm{rpm}$. It can be also noted from the Figure 10, that further increase in impeller speed (to $250 \mathrm{rpm}$ ) caused a considerable fall in heat production. In the similar way, heat productions at varying oxygen flow rates were analyzed and results were shown in Figure 11. From the Figure 11, it can be seen that increasing the oxygen flow from $0.5 \mathrm{l} \mathrm{min}^{-1}$ to $1 \mathrm{l} \mathrm{min}^{-1}$ caused a two fold increase in heat generation. Increasing the oxygen flow to $1.5 \mathrm{l} \mathrm{min}^{-1}$ resulted an observable fall in heat generation. Hence $1 \mathrm{l} \mathrm{min}^{-1}$ oxygen flow rate was found to be optimum for the better growth of $P$. aeruginosa in NB media. Thus from the calorimetric studies it can be stated that the optimum conditions for growth of $P$. aeruginosa are at $200 \mathrm{rpm}$ (impeller speed) and $1 \mathrm{l} \mathrm{min}^{-1}$ (oxygen flow) respectively. The $k_{L} a$ value obtained under the above conditions was found to be maximum (0.559 $\min ^{-1}$ ).

\section{Correlation of volumetric mass transfer coefficient $\left(k_{L} a\right)$ with impeller speed $(\mathrm{N})$ and Superficial gas velocity $\left(\mathrm{V}_{\mathrm{s}}\right)$}

It can be found from experimental data that $k_{L} a$ depends on impeller speed and attains a maximum value at $200 \mathrm{rpm} .1 \mathrm{l}$ $\min ^{-1}$ oxygen flow showed a maximum $k_{L} a$ value when compared to other flow rates.

In order to determine the influence of operational conditions $\left(V_{s}, \mathrm{~N}\right)$ on volumetric mass transfer coefficient values have been considered and $k_{L} a$ values have been correlated according to the relationship given below Equation 8,

$$
k_{L} a \alpha\left(N^{3} D^{2}\right)^{\alpha}\left(V_{s}\right)^{\beta}
$$

In the above equation, the influence and the relative importance of the considered variables are determined by the coefficients $\alpha$ and $\beta$ values. The values of these coefficients are specific for each microorganism type or morphology. The exponential relationship between $k_{L} a$ and impeller speed ( $\mathrm{N}$ ) for this study is given by Equation (9),

$$
k_{L} a \alpha\left(N^{3} D^{2}\right)^{0.24}
$$

The statistical values of $R^{2}$ and standard error $(\sigma)$ obtained by using the data were 0.9997 and 0.00016 respectively. In the absence of power measurement equipment, the 
exponents of $N^{3} D^{2}$ were obtained as representation of the power number per unit volume $\left(\frac{P}{V_{L}}\right)$. The exponent of $N^{3} D^{2}$ obtained from this study ( $\left.\alpha=0.24\right)$, is within the range reported in the literature $(0.16-0.68)$. The wide variation of $\alpha$ is related to the geometry of the vessel (the proportionality of impeller diameter to vessel diameter, tank bottom geometry, tank liquid height, etc.) employed by different researchers.

The exponential relationship between $k_{L} a$ and superficial oxygen velocity $\left(V_{\mathrm{s}}\right)$ for this study is given by Equation (10),

$$
k_{L} a \alpha\left(V_{s}\right)^{0.41}
$$

The statistical values of $R^{2}$ and standard error $(\sigma)$ obtained by using the data were 0.9995 and 0.00029 respectively. The exponent ( $\beta=0.41$ ) representing the dependence of $k_{L} a$ on the superficial gas velocity $\left(V_{\mathrm{s}}\right)$ was compared with the literature values. Previous investigators (Hyman and Bogaerde, 1960) obtained the values of the exponent on the superficial gas velocity in the range 0.17 to 0.67 , depending on the agitator speed and the geometry of the equipment. The exponent obtained from this study again well corroborates to the reported values. A satisfactory linear correlation (Figure 12) was observed between volumetric mass transfer coefficient $\left(k_{L} a\right)$ and metabolic heat (q) at optimized process conditions (200 rpm \& $1 \mathrm{l} \mathrm{min}^{-1}$ ) as follows

$$
k_{L} a=0.0268(q)+0.3176
$$

\section{CONCLUDING REMARKS}

Evaluation of the experimental data showed that $k_{L} a$ values are affected by process variables such as impeller speed, oxygen flow rate and geometry of the stirrer. Increase in impeller speed resulted in four-fold increase in $k_{L} a$ value and the increase in oxygen flow rate caused a two-fold rise in $k_{L} a$ values. Turbine-type impeller showed maximum oxygen transfer compared to Rushton-turbine type. The $k_{L} a$ values obtained from the data of oxygen absorption were used to establish correlations as a function of the process variables. The exponents of power number $\left(N^{3} D^{2}\right)$ and superficial gas velocity $\left(V_{s}\right)$ found for NB growth media were 0.24 and 0.41 respectively, are in good agreement with the exponents given in the literature. Calorimetric experiments revealed that the growth of $P$. aeruginosa in NB media was found to follow the heat generated due to metabolic activity. Both $q_{o_{2}}$ and metabolic heat are found to be influenced greatly by growth phases of $P$. aeruginosa and attained their maximum value at the middle of the exponential phase. Heat data (q) were found to correlate well with volumetric mass transfer coefficient $\left(k_{L} a\right)$ and a linear correlation was obtained at optimized process conditions. The correlations obtained in this study clearly indicates that both respirometric and calorimetric results from biocalorimetric experiments could be used for effective scale-up and design of biological reactions to large scale.

\section{ACKNOWLEDGMENTS}

One of the authors Mr. S. Senthilkumar is grateful to CSIR, New Delhi for the SRF fellowship. The author thanks the Director, CLRI for his kind permission to publish this work. The author also wishes to express his gratitude to Prof. K.S. Gandhi for his useful suggestion and Prof. N.R. Rajagopal for his constant encouragement.

\section{REFERENCES}

CALIK, Güzide; VURAL, Halil and OZDAMAR, Tunçer. Bioprocess parameters and oxygen transfer effects in the growth of Pseudomonas dacunhae for L-alanine production. Chemical Engineering Journal, May 1997, vol. 65, no. 2, p. 109-116.

CHISTI, Yusuf and JAUREGUI-HAZA, Ulises J. Oxygen transfer and mixing in mechanically agitated airlift bioreactors. Biochemical Engineering Journal, March 2002, vol. 10, no. 2, p. 143-153.

GALACTION, A.-I.; CASCAVAL, D.; ONISCU, C. and TURNEA, M. Prediction of oxygen mass transfer coefficients in stirred bioreactors for bacteria, yeasts and fungus broths. Biochemical Engineering Journal, August 2004, vol. 20, no. 1, p. 85-94.

GARCIA-OCHOA, Félix and GOMEZ-CASTRO, Emilio. Mass transfer coefficient in stirrer tank reactors for xanthan gum solutions. Biochemical Engineering Journal, January 1998, vol. 1, no. 1, p. 1-10.

GARCIA-OCHOA, F.; GOMEZ-CASTRO, E. and SANTOS, V.E. Oxygen transfer and uptake rates during xanthan gum production. Enzyme and Microbial Technology, November 2000, vol. 27, no. 9, p. 680-690.

GARCIA-OCHOA, Felix and GOMEZ-CASTRO, Emilio. Prediction of gas-liquid mass transfer coefficient in sparged stirred tank bioreactors. Biotechnology and Bioengineering, December 2005, vol. 92, no. 6, p. 761-772.

HARIRI, M. Hossein; LEWIS, Robert A.; LONIS, Timothy R.; PARKER, Bruce E. and STEPHENSON, Kay A. The effect of operating conditions in a reaction calorimeter. Thermochimica Acta, December 1996, vol. 289, no. 2, p. 343-349.

HUGH, Rudolph and LEIFSON, Einar. The taxonomic significance of fermentative versus oxidative metabolism of carbohydrates by various gram-negative bacteria. Journal of Bacteriology, January 1953, vol. 66, no. 1, p. 24-26.

HYMAN, D. and BOGAERDE, J.M. Small bench scale stirred reactors. Industrial Engineering Chemistry, September 1960, vol. 52, no. 9, p. 751-759. 
KOVACS, Nicholas. Identification of Pseudomonas pyocyanea by the oxidase reaction. Nature, September 1956, vol. 178, no. 4535, p. 703.

MARISON, I.W.; LIU, J.S.; AMPUERO, S.; VON STOCKAR, U. and SCHENKER, U. Biological reaction calorimetry: Development of high sensitivity biocalorimeters. Thermochimica Acta, January 1998, vol. 309, no. 1 , p. 157-173.

MONTES, Francisco J.; CATALAN, Jacinto and GALAN, Miguel A. Prediction of $k_{\mathrm{L}} a$ in yeast broths. Process Biochemistry, September 1999, vol. 34, no. 6-7, p. 549-555.

NISHIKAWA, Masabumi; NAKAMURA, Masao and HASHIMOTO, Kenji. Gas absorption in aerated mixing vessels with non-Newtonian liquid. Journal of Chemical Engineering of Japan, June 1981, vol. 14, no. 3, p. 227232.

OZBEK, Belma and GAYIK, Sevgi. The studies on the oxygen mass transfer coefficient in a bioreactor. Process Biochemistry, March 2001, vol. 36, no. 8-9, p. 729-741.

RICHARDS, J.W. Studies in aeration and agitation. Progress in Industrial Microbiology, 1961, vol. 3, p.143172.

SINGH, V. On-line measurement of oxygen uptake in cell culture using the dynamic Method. Biotechnology and Bioengineering, April 1996, vol. 52, no. 3, p. 443-448.

VANT RIET, Klass. Review of measuring methods and results in nonviscous gas-liquid mass transfer in stirred vessels. Industrial and Engineering Chemistry Process Design and Development, 1979, vol. 18, no. 3, p. 357-364.

VOISARD, D.; VON STOCKAR, U. and MARISON, I.W. Quantitative calorimetric investigation of fed-batch cultures of Bacillus sphaericus 1593M. Thermochimica Acta, October 2002, vol. 394, no. 1-2, p. 99-111.

WU, Hua. An issue on applications of a disk turbine for gas-liquid mass transfer. Chemical Engineering Science, September 1995, vol. 50, no. 17, p. 2801-2811. 


\section{APPENDIX}

\section{FIGURES}

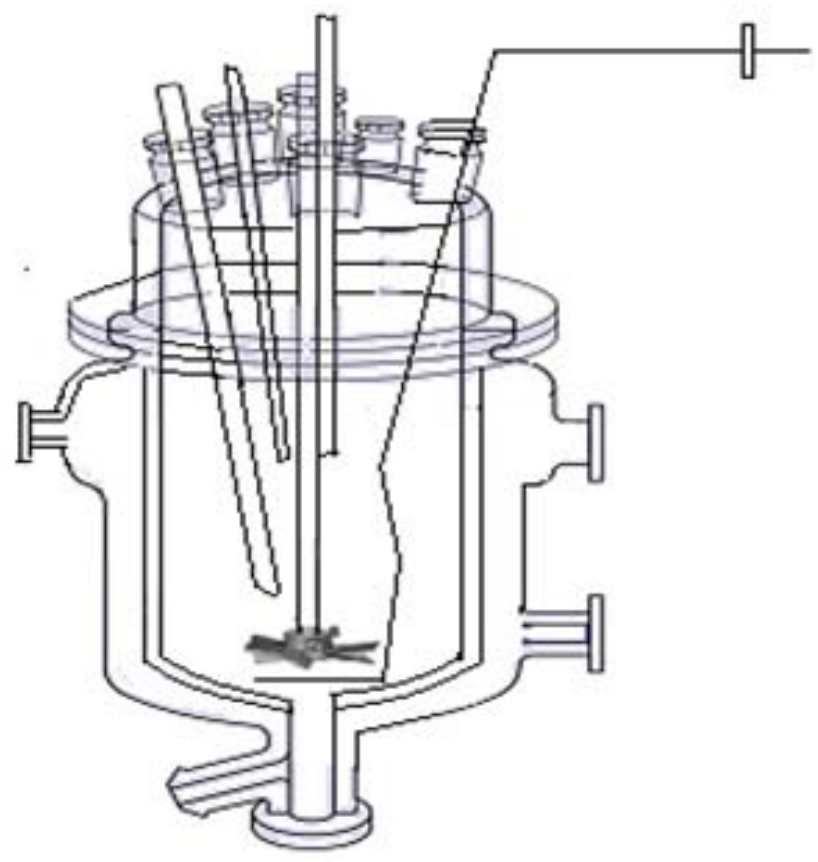

Figure 1. Schematic representation of Biological Reaction Calorimeter (Bio-RC1).

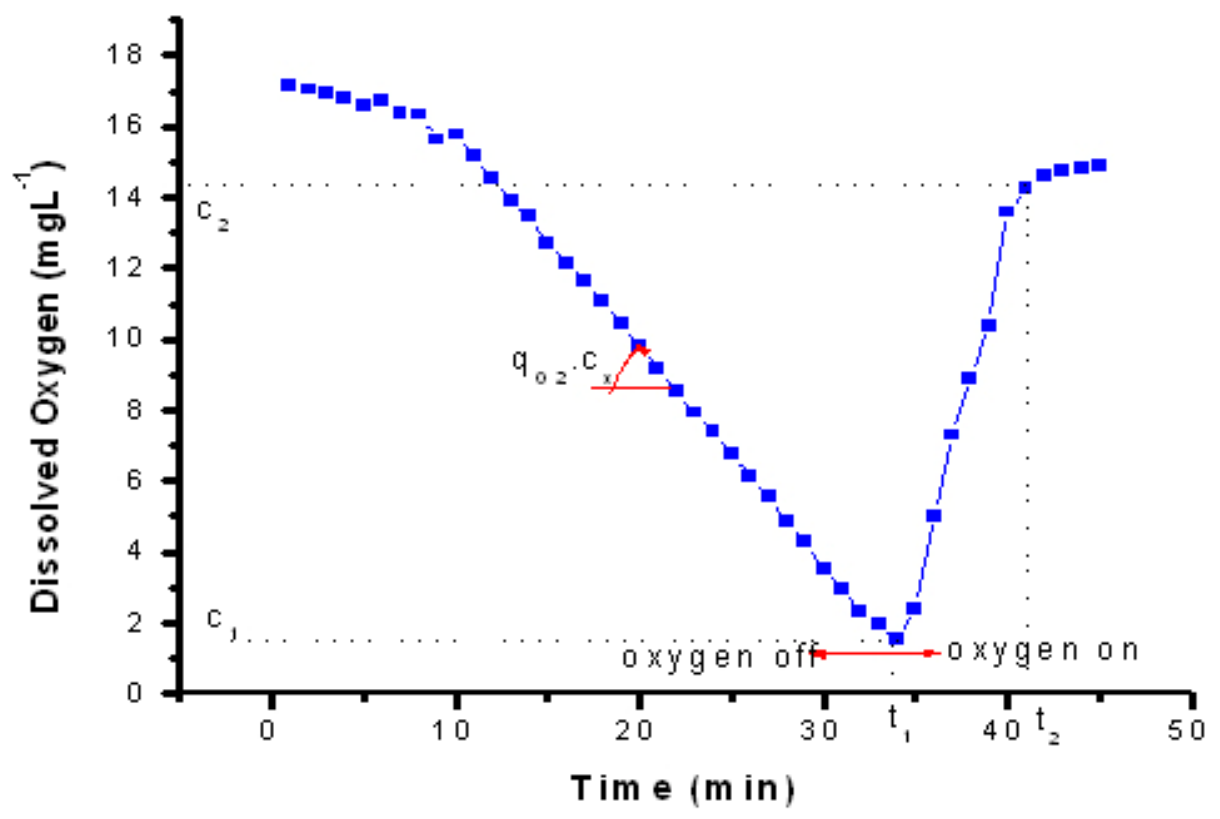

Figure 2. Typical results obtained during dynamic method for $k_{L} a$ and OUR determination during cultivation of Pseudomonas aeruginosa. 


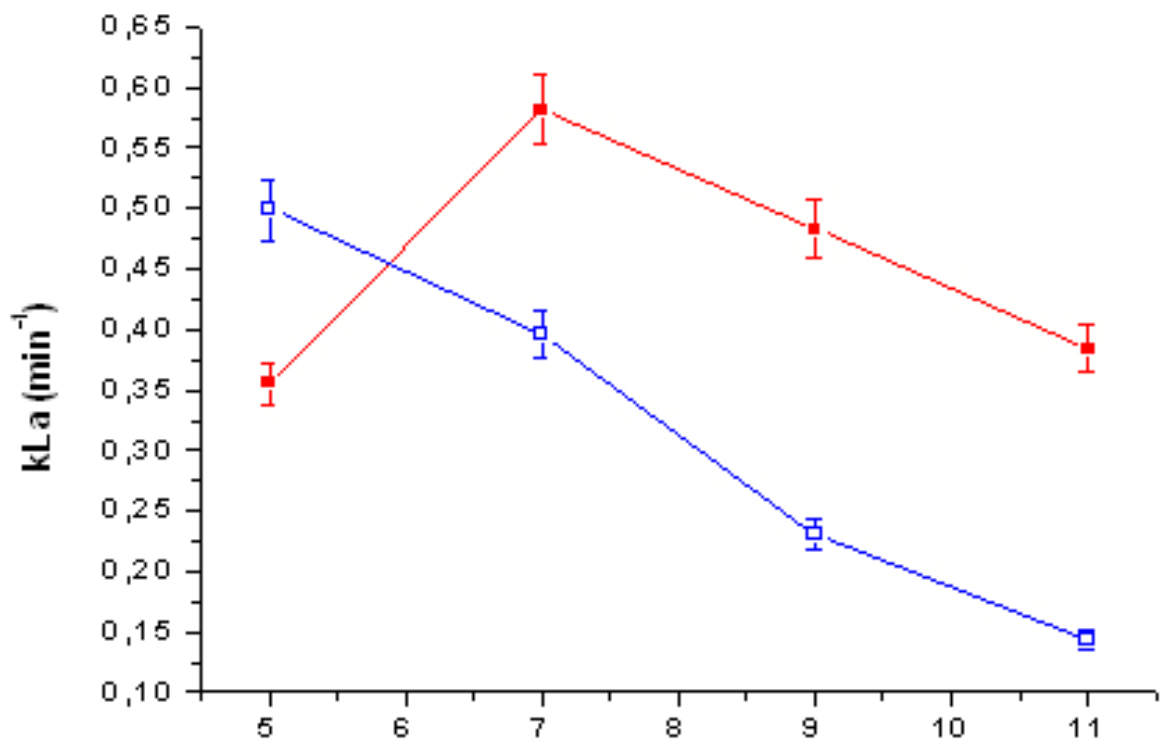

Time (hrs)

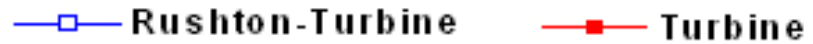

Figure 3. Influence of impeller type on volumetric mass transfer coefficient.

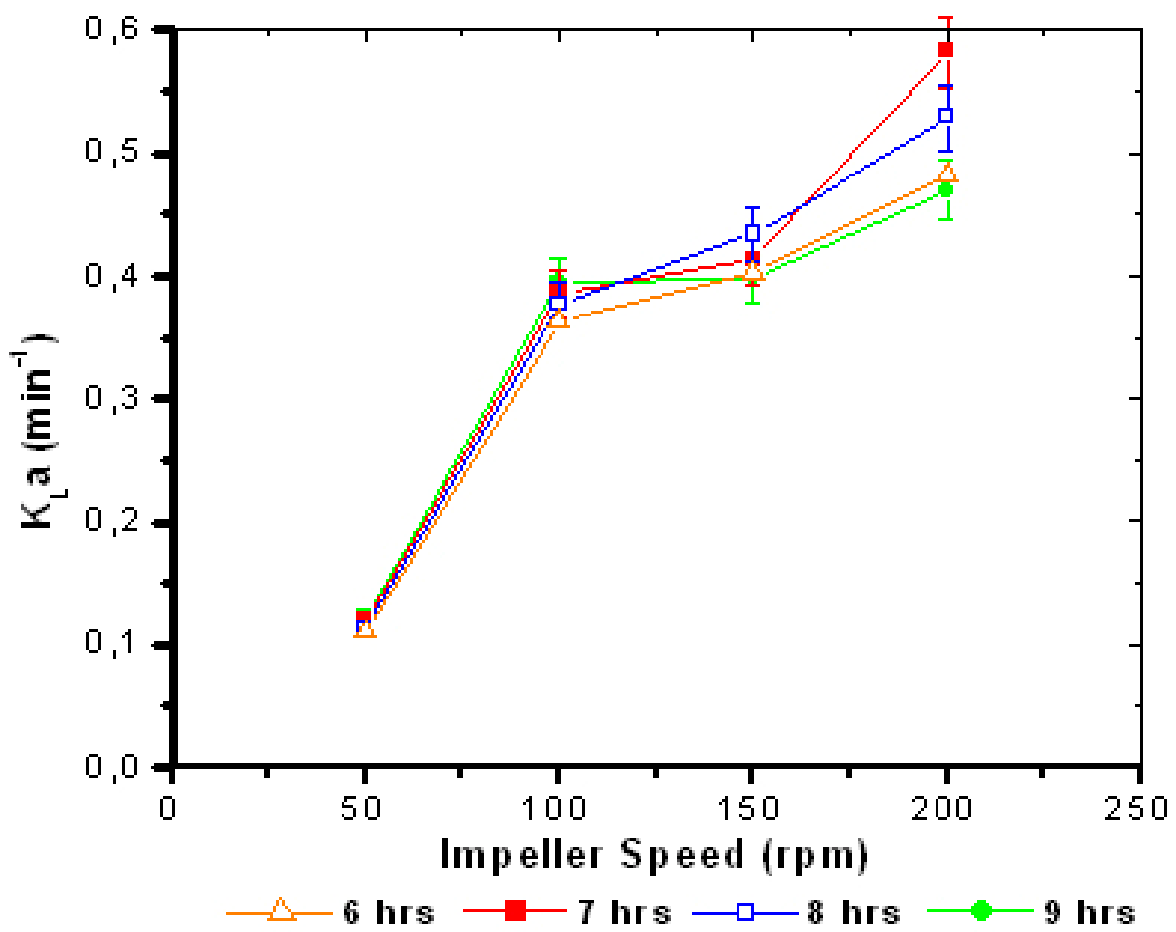

Figure 4. Influence of turbine type impeller speed on volumetric mass transfer coefficient: 6 hrs ( $\triangle$ ), 7 hrs ( $\square$ ), 8 hrs ( $\square)$ and 9 hrs (•). 


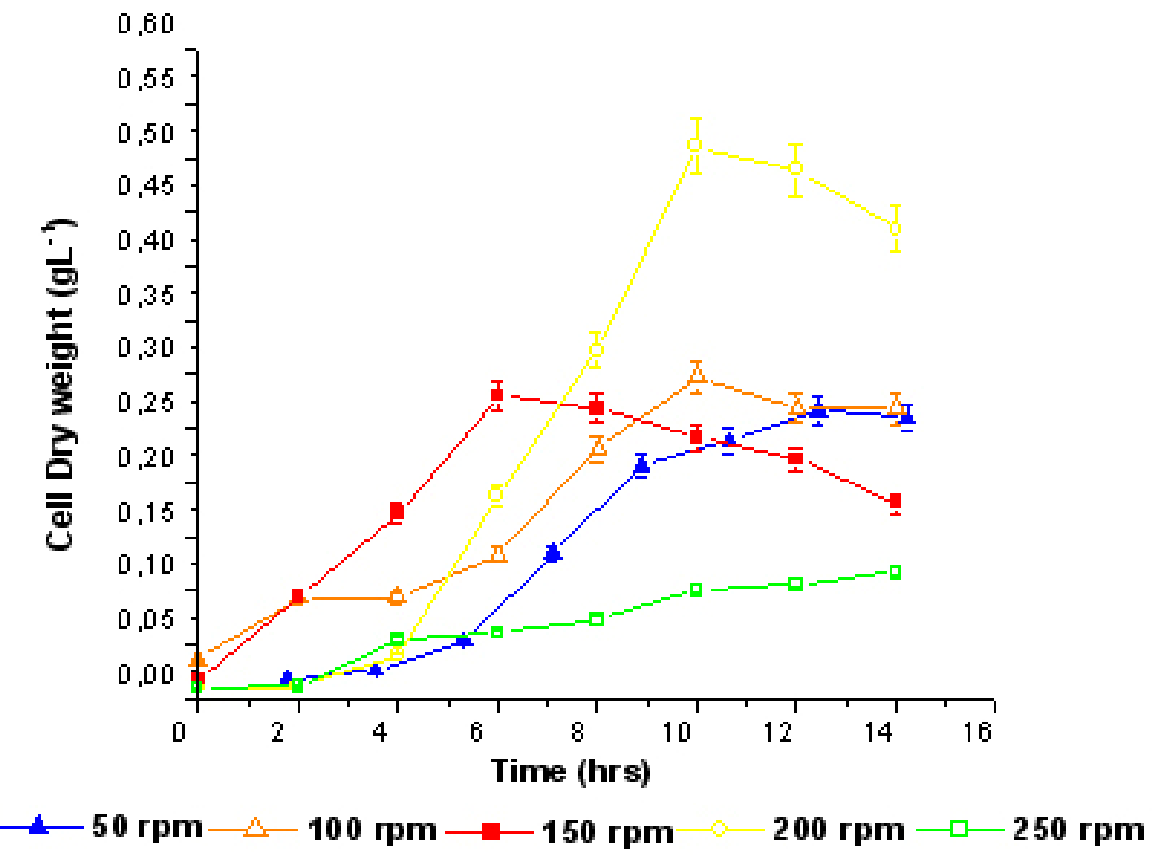

Figure 5. Effect of turbine type impeller speed on growth of $P$. aeruginosa in nutrient broth.

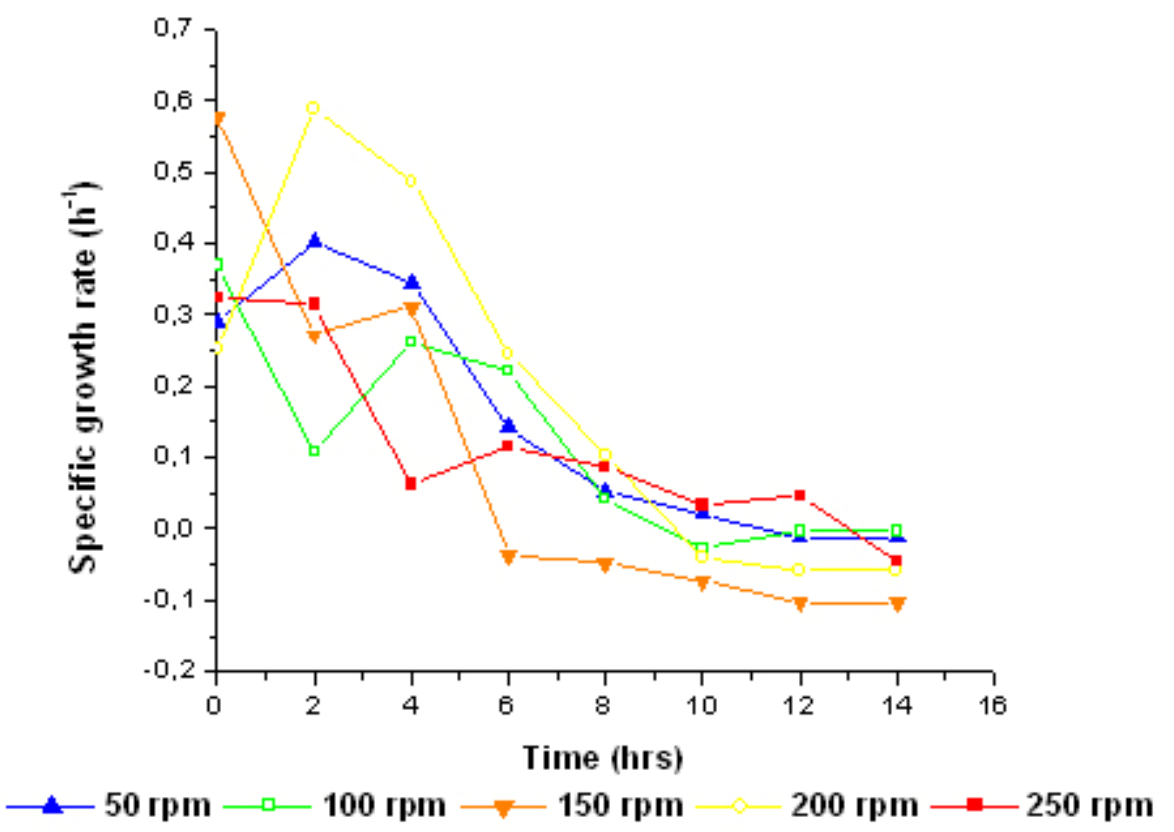

Figure 6. Effect of turbine type impeller speed on specific growth rate of $P$. aeruginosa. 


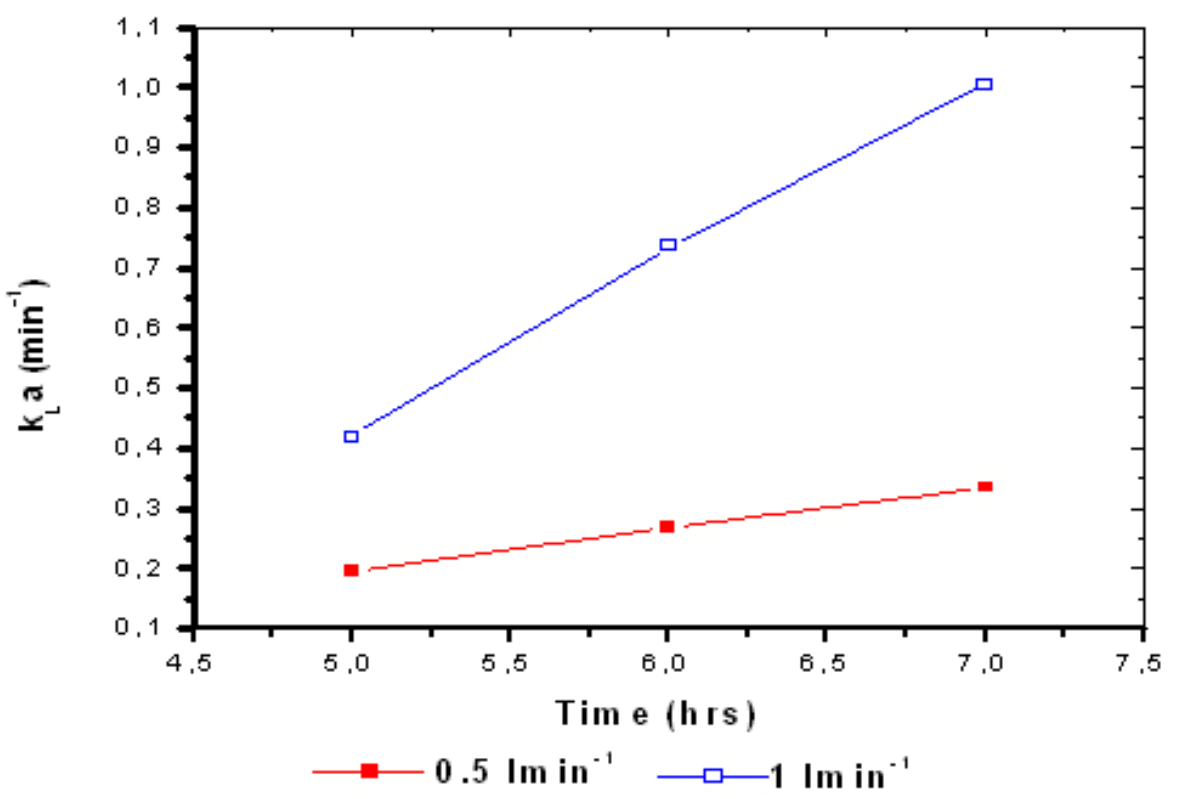

Figure 7. Influence of superficial gas velocity on volumetric mass transfer coefficient.

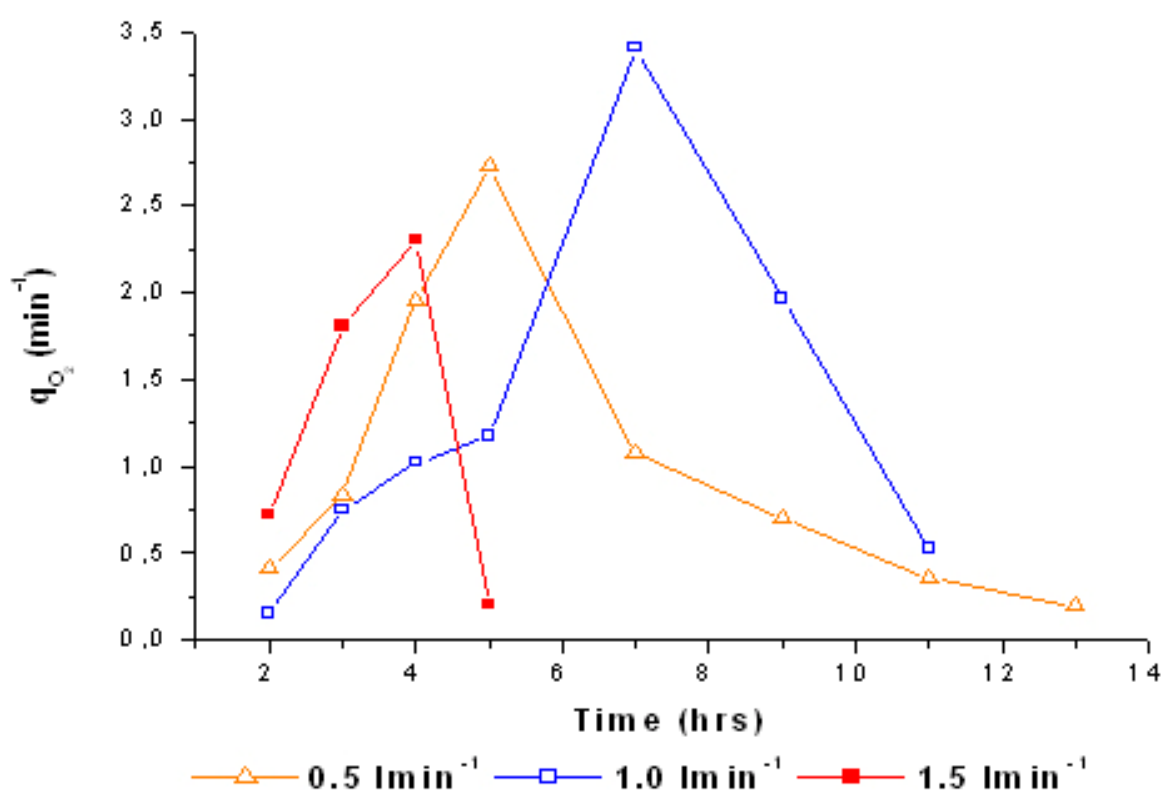

Figure 8. Influence of superficial gas velocity on specific OUR ( $9 a_{1}$ ). 


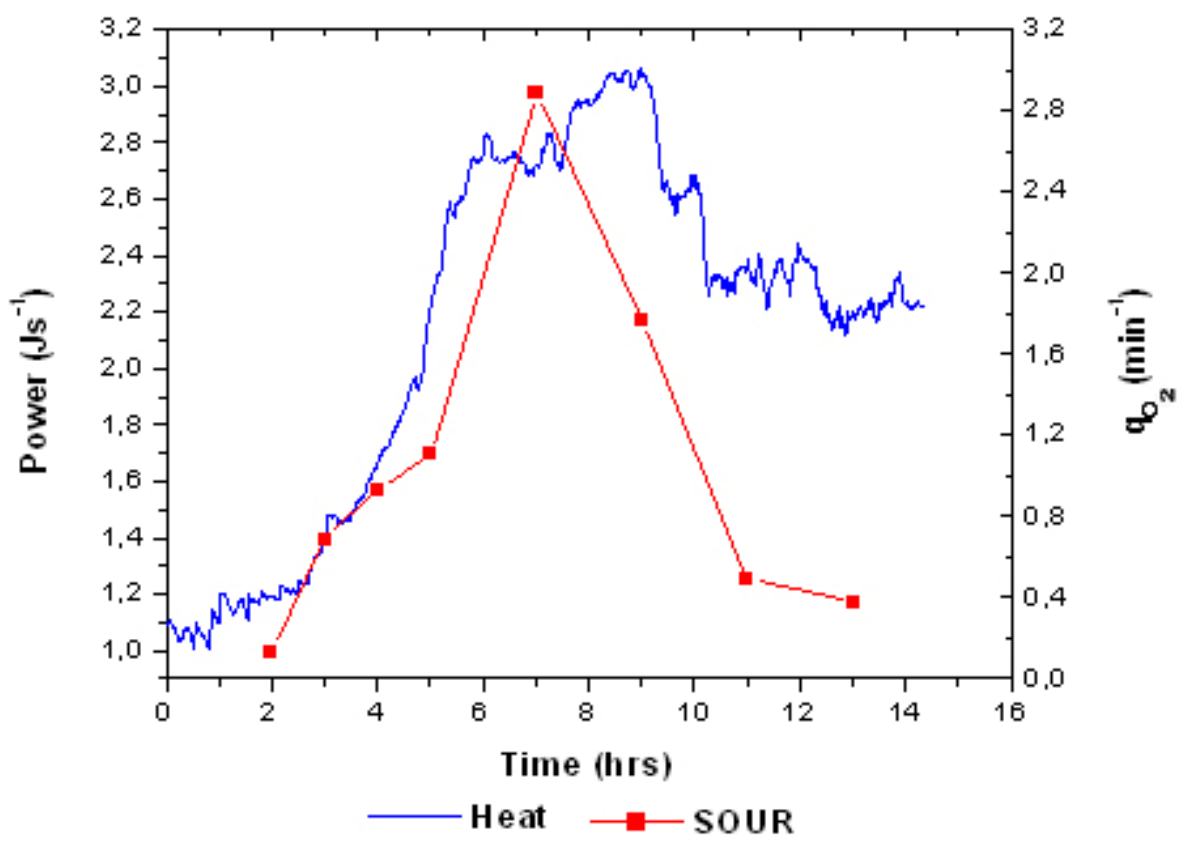

Figure 9. Plot showing the power-time curve (-) and specific oxygen uptake ( $\$$ - $\square$ ') of P.aeruginosa cultivated under optimized conditions (Impeller speed $200 \mathrm{rpm}$, oxygen flow $1 \mathrm{Lmin}^{-1}$ ).

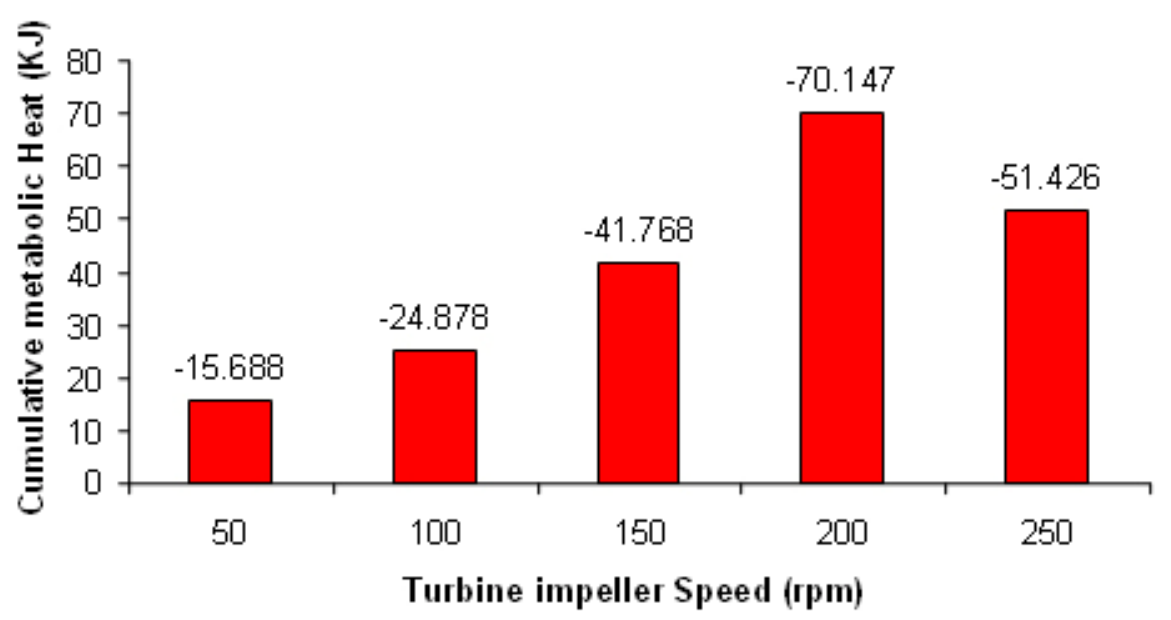

Figure 10. Comparative plot describing the variation in metabolic heat generation due to growth of $P$. aeruginosa at different impeller speeds. 


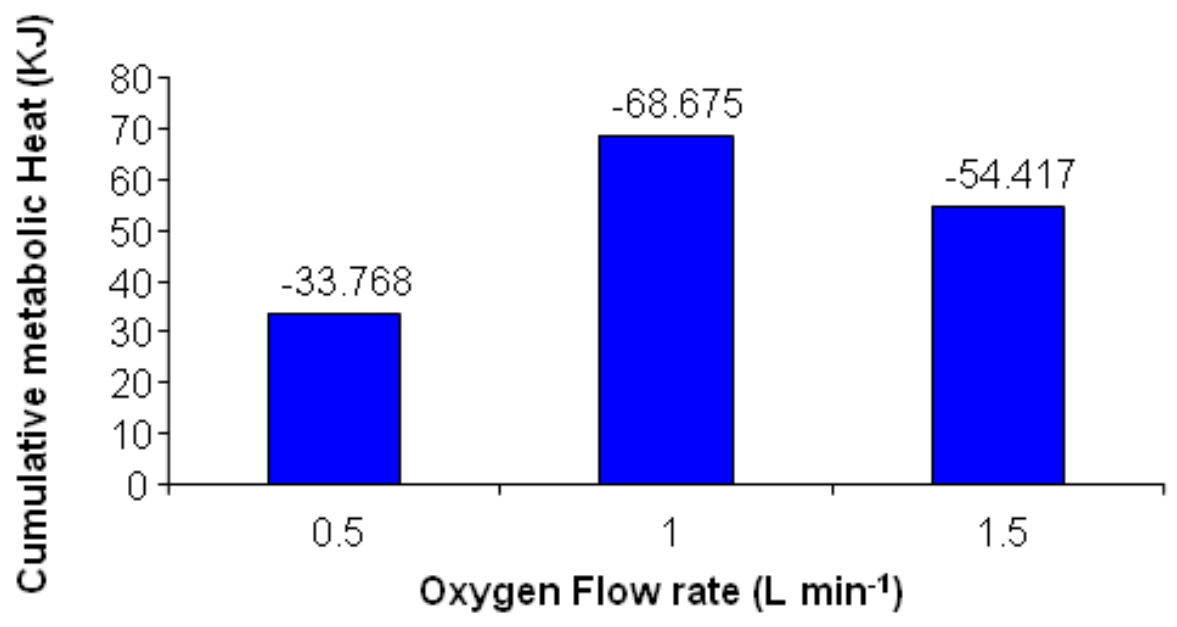

Figure 11. Comparative plot describing the variation in metabolic heat generation due to growth of $P$. aeruginosa at different oxygen flow rates.

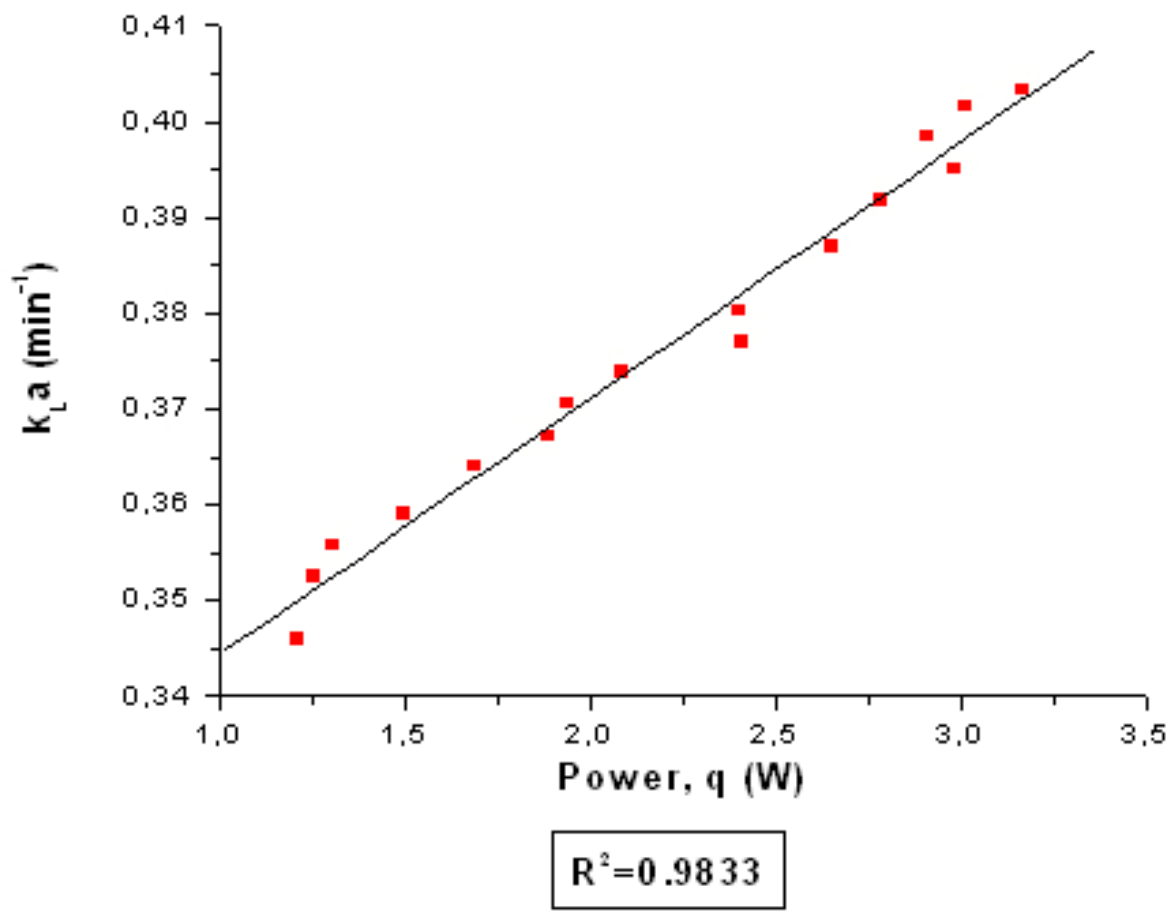

Figure 12. Plot showing a linear relation between metabolic heat $(q)$ and volumetric mass transfer coefficient $\left(k_{L} a\right)$ at optimized process conditions. 